\section{Nilo Peçanha e seu cão Jicky: sentidos culturais e políticos de uma relação}

\author{
Natascha Stefania \\ Carvalho de Ostos [*]
}

[*] Instituto René Rachou/Fundação Oswaldo Cruz Minas (IRR/Fiocruz Minas). Belo Horizonte (MG), Brasil.nataschaostos@hotmail.com

ORCID: https://orcid.org/0000-0002-4531-1924
Resumo: $\mathrm{O}$ artigo analisa a relação de Nilo Peçanha com seu cão de estimação, Jicky. O vínculo existente entre esses dois seres individualizados, nas décadas iniciais do século XX, aponta para diversos aspectos da interação histórica entre homens e animais. Como líder em evidência e presidente da República, o relacionamento de Nilo Peçanha com seu cachorro foi representado na imprensa, explicitando sentidos culturais e políticos que remetiam tanto ao contexto da época como à imagem do advogado fluminense. Jicky tornou-se personagem do cenário público da Primeira República, encarnando, juntamente com o dono, novas possibilidades afetivas e velhas práticas políticas. As fontes utilizadas na pesquisa foram notícias de jornais e revistas, charges e documentos do acervo do Museu da República.

Palavras-chave: Primeira República; Nilo Peçanha (18671924); História dos animais.

\section{Nilo Peçanha and his dog Jicky: cultural and political meanings of a relationship}

\begin{abstract}
The article examines Nilo Peçanha's relationship with his pet dog, Jicky. The bond between these two individualized living beings in the early decades of the twentieth century points to various aspects of the historical interaction be tween humans and animals. As a prominent leader and President of the Republic, Nilo Peçanha's relationship with his dog was represented in the press, highlighting cultural and political meanings that referred to the context of the time and the image of the politician. Jicky became a "public figure" in the First Republic, personifying, along with its owner, new affective possibilities and old political practices. The sources used in the research were news from newspapers and magazines, cartoons and documents from the collection of the Museum of the Republic.
\end{abstract}

Keywords: First Republic; Nilo Peçanha (1867-1924); Animal history. 

escritor Pedro Nava entrelaça em suas obras acontecimentos pessoais com eventos e situações que marcaram o Brasil ao longo do século XX. No livro Chão de ferro ele conta sobre as férias que passou em Niterói, Rio de Janeiro, em fins da década de 1910, ocasião em que avistou Nilo Peçanha. Um dos aspectos do político fluminense recordado por Nava foi a sua relação próxima, e conhecida do público, com um cão de estimação.

Todo seu carinho e da esposa pertenciam ao cachorrinho peludo que criavam e que era chamado Jiqui. Esse nome era repetido com unção pelos engrossadores que viviam presenteando o totó com coleiras luxuosas onde ele vinha gravado em plaquinhas de prata ou de ouro. Todos adoravam o Jiqui... (Nava, 2001, p. 118).

Nava publicou Chão de ferro em 1976, de forma que a associação entre Nilo Peçanha e seu cão Jicky foi algo que marcou o escritor e mereceu registro. Mas, tal recordação seria uma impressão juvenil, reelaborada anos depois e plasmada em um roteiro romantizado, protagonizado por um homem poderoso e seu cão? Ou a subjetividade da memória se referia, nesse caso, a um traço histórico socialmente partilhado? O trecho extraído da obra remete à Primeira República brasileira (1889-1930), mais especificamente ao fim da década de 1900 e meados dos anos 1910. Pesquisa documental indica que esse "cachorrinho peludo" realmente figurou em meio ao repertório político nacional, povoando as páginas da imprensa, representado em fotografias, textos e charges, compondo com seu dono, Nilo Peçanha, uma dupla que encarnou sentidos políticos e culturais. Analisamos como a relação entre Nilo Peçanha e seu cão levou à construção do personagem Jicky em jornais e revistas, evidenciando como o animal não apenas foi revestido de sentidos advindos da posição política e social de Nilo Peçanha, como também ajudou a compor a imagem do político, tendo em vista as ideias e sensibilidades da época sobre os cães.

Esta pesquisa entrelaça a história política (Rémond, 2003) com os estudos dos animais (Fudge, 2002), explicitando como representações sociais constroem-se na intrincada conexão entre a materialidade e as ideias, de modo que animais humanos e não humanos interagem em um mundo complexo, produzindo relações que escapam dos esquemas de pensamento categorizados. O fenômeno político, longe de ser apenas institucional e racional, também mobiliza emoções para construir narrativas e imagens (Pesavento, 2005). A experiência sensível, mesmo de difícil apreensão, não pode ser excluída das análises históricas, sob pena de mutilar parte do vivido humano. Como diz Carlo Ginzburg, "A história (as

${ }^{1}$ Nas fontes o nome do cão é grafado de diferentes maneiras. Optamos pela versão "Jicky" por ser a forma mais comum na documentação. 
relações entre fenômenos artísticos e história política, religiosa, social, das mentalidades etc.), expulsa silenciosamente pela porta, torna a entrar pela janela" (1989, p. 92).

Além de considerarmos os animais como uma ideia constantemente reelaborada pelos humanos, objetivamos levar em conta a materialidade dos seres vivos, sua participação na história como presença concreta que, mesmo entrando na narrativa histórica por meio do olhar humano, possuem existência própria, sendo elementos fundamentais na urdidura do mundo real-representado. Não é incomum a historiografia se debruçar sobre o tema das metáforas animais projetadas sobre identidades políticas (Morel, 2005). Este artigo contempla tal viés analítico, mas não se limita a ele, já que propomos compreender não apenas como as ideias culturais sobre os cães podem ser mobilizadas para traçar identidades humanas, como também analisar a correlação específica entre dois seres individualizados, Nilo Peçanha e Jicky. Claro está que somente conhecemos Jicky por meio da perspectiva humana, seu comportamento é descrito pela linguagem e cultura dos homens, mas isso não altera o fato de que ele existiu, foi presença viva, interagiu com pessoas, provocou reações, e se Jicky não seria Jicky sem Nilo Peçanha, este seria outro sem o seu cão. E aqui não se trata apenas de uma faceta pessoal, mas também política, já que a relação entre o presidente e seu cachorro foi dimensionada como elemento de interesse para a caracterização do perfil público de Nilo Peçanha e dos códigos de comportamento político que cercaram sua pessoa.

O período estudado abrange o final da década de 1900 até meados do decênio de 1910, quando Nilo esteve em evidência política, coincidindo com a existência do seu animal de estimação. A documentação levantada abrange jornais e revistas da época, incluindo notícias, crônicas, charges, notas e fotografias, além de fontes do acervo do Museu da República.

\section{Nilo Peçanha e Jicky: traços biográficos de uma relação}

O historiador Éric Baratay, no livro Biographies animales (2017), assinala que a possibilidade de reconhecer um animal na sua individualidade, e não apenas como representante de certa espécie, integra o contexto histórico de interesse crescente pelos feitos e gestos dos animais. Em termos científicos a etologia tem contribuído para o debate ao ir além do estudo comportamental das espécies (como grupo), para incluir investigações sobre a singularidade de espécimes, apontando para a diferenciação dos animais tanto em termos coletivos quanto individuais (Lestel, Brunois, Gaunet, 2006). Do ponto de vista social, o processo de individualização dos bichos (sua percepção como seres únicos), está vinculado ao contexto de crescimento do número de animais de estimação, principalmente no século XX. Apesar de lançarmos mão, com base na documentação, de suposições sobre a vida de Jicky, nos interessa menos biografar duas existências em paralelo do que compreender a dinâmica da relação entre um homem e seu cão, e como ela foi representada pela imprensa da época. 
Em outros termos, o que captura nossa atenção aqui, não pode ser reduzido ao comportamento dos animais com os quais os humanos interagem ou às representações que os humanos têm desses animais. O que interessa é saber como humanos e animais se comportam juntos, de modo a configurar uma entidade humano-cão que é aquela verdadeiramente relevante (Lestel, Brunois, Gaunet, 2006, p. 167; tradução da autora).

Assim, mais do que traçar um perfil sobre Nilo Peçanha e Jicky, isolando-os em trajetórias individuais, selecionamos elementos da existência desses dois seres vivos que, no nosso entender, possibilitaram sua aproximação. Não pretendemos naturalizar como destino o encontro dos dois, e sim explicitar a ideia de que, se Nilo e Jicky não estavam fadados um ao outro, a sua reunião tampouco foi fortuita. No nosso entender, estudar a relação específica entre um homem e um cão é uma oportunidade para ampliar as bases do conhecimento histórico, compreender que "nunca estivemos sozinhos" (Duarte, 2019, p. 37), pois em inúmeras situações os animais foram coautores de empreendimentos e narrativas que julgamos exclusivamente humanos. Essas relações não se deram apenas em bases coletivas - como no processo de domesticação de espécies, na incorporação dos animais em concepções religiosas e expressões artísticas -, mas também na interação entre seres vivos individualizados. Ocorre que é mais difícil encontrar documentação capaz de subsidiar o estudo da relação pessoal entre um ser humano e um animal em particular. Nesse sentido, o excepcional aqui não é o vínculo entre Nilo e seu cão - pois os animais de estimação eram comuns no início do século XX -, e sim o registro dessa relação. No caso em pauta, é evidente que foi a posição social e política de Nilo Peçanha que possibilitou a inscrição de Jicky na história.

Vamos explorar indícios da trajetória desses dois viventes que possibilitem compreender como suas existências foram entrelaçadas, abrangendo tanto a dinâmica da vida de Nilo Peçanha, como aspectos sociais e culturais da época no que diz respeito às sensibilidades sobre os cães, de forma a caracterizar o contexto organizador dessa relação. Com base em indícios documentais levantaremos algumas hipóteses sobre a vida de Jicky na tentativa de configurar elementos do seu cotidiano.

Nilo Procópio Peçanha, nascido em Campos dos Goytacazes, Rio de Janeiro, na zona rural, no ano de 1867 , pertencia a uma família de poucas posses (seu pai era padeiro), mas que tinha relações com a elite fluminense por parte de mãe. Essa origem mesclada serviu como munição tanto para seus detratores, que escarneciam de sua procedência relativamente humilde, como trunfo para seus apoiadores, em razão dela supostamente indicar uma maior proximidade com o povo. Soma-se à gênese de Nilo Peçanha o fato dele ser negro, "mulato" (segundo designações do período), e apesar do político não assumir tal condição, o repertório da época está cheio de alusões racistas à cor da sua pele.

A origem remediada e a condição de afrodescendente são elementos atípicos para um político destacado da Primeira República, mas isso não tornava Nilo alguém à margem do 
círculo da elite fluminense. Sua família tinha contatos e relações de parentesco com a sociedade abastada campista. Nilo Peçanha seguiu a formação dos jovens privilegiados da época, bacharel pela Faculdade de Direito do Recife, "Iniciou-se na política ao se engajar nos movimentos abolicionista e republicano em Campos, onde ajudou a instalar o Partido Republicano" (Ferreira, s.d, s.p). Com a Proclamação da República foi deputado constituinte, sendo, posteriormente, deputado federal e senador em outras legislaturas; além de presidente do estado do Rio de Janeiro em duas ocasiões (1903-1906 e 1914-1917). Foi vice-presidente da República no mandato de Afonso Pena (1906-1909), assumindo, com a morte de Pena, o cargo de presidente do país entre junho de 1909 e novembro de 1910 (Ferreira, s.d, s.p).

Nilo Peçanha casou-se com Ana de Castro Belisário Soares de Sousa, conhecida após as bodas como Anita Peçanha. Sua família, de posses, pertencia à aristocracia imperial por parte de pai e mãe. A corte de Nilo à Anita não foi apreciada pela família da moça (Tinoco, 1962, p. 58), que demonstrou repulsa em razão da situação remediada do pretendente e, claro, preconceito por sua cor, principalmente na pessoa da matriarca. Mas a moça, a quem se reputava personalidade forte, contrariou os desejos familiares e casou-se com Nilo, constando que a noiva e sua mãe nunca mais se falaram. O casal parece ter tido uma união feliz, mas sofreu grande revés pela perda de filhos (natimortos ou que sobreviveram poucas horas), motivo de sofrimento para os dois (Tinoco, 1962, p. 85). Tal fato é relevante porque a falta de filhos parece ter reforçado a transferência dos afetos de Nilo Peçanha para os bichos, "Sem prole a que se dedicar, dedicou-se aos animais" (Tinoco, 1962, p. 85).

O gosto de Nilo pelos bichos era assinalado como de longa data. Brígido Tinoco conta que, quando criança, Nilo possuía um galo de estimação, a quem levou para a escola no primeiro dia de aula (1962, p. 17). A imprensa destacava o cuidado que devotava a "seus bichos, como designa todos os animais que lhe pertencem. O Dr. Nilo Peçanha quer bem aos animais, procura-os, afaga-os, indaga do seu estado, providencia para que nada lhes falte". ${ }^{2}$ Esses animais ficavam em sua propriedade rural no interior fluminense, eram bichos domésticos e alguns silvestres. Nilo teria despedido um empregado por matar um macaco pertencente a um grupo que ele costumava alimentar. Também consta que na fazenda ele possuía um marreco que o seguia por todo lado (Tinoco, 1962, p. 86), além de cavalos e cães. Mesmo que o perfil do político como homem compassivo tenha sido exagerado por biógrafos e simpatizantes, não há dúvida do apreço que ele tinha pelos animais.

Nilo Peçanha possuía mais de um cão de estimação, cada qual com acesso diferenciado às dependências da casa. No Museu da República existem fotografias de Nilo acompanhado de cachorros. As imagens atestam que os animais integravam o círculo íntimo da família,

2 O Snr. Nilo Peçanha na intimidade. Almanach do Paiz, ano I, 1910, p. 94 
no que parecia ser mais um elemento de união do casal, privado de filhos. A partir de meados do século XIX era comum a comparação de animais de estimação com crianças, infantilizados em razão de sua dependência para terem abrigo e comida, e pelo comportamento espontâneo (Ostos, 2019, p. 54-55). Brígido Tinoco narra que, em 1901, Nilo Peçanha esteve preocupado pelo seu cão Beijo, muito doente, de tal forma que recorreu aos préstimos de ninguém menos do que o ministro da Fazenda da época, Joaquim Murtinho, político influente, médico e homeopata (Melo, Fanaia, s.d, s.p.). Cartas trocadas entre os dois tratavam da situação do cão. Mas o cachorro morreu, causando consternação em Nilo, que em missiva ao pai, transcrita por Tinoco, escreveu:

Esgotei todos os recursos; o Ministro da Fazenda, que é muito meu camarada e que tanto apreciava e queria o Beijo, empregou todos os esforços e todas as indicações de sua ciência. Morreu de um mal de cadeiras, o pobre! A sua agonia, tão lenta, tão dolorosa - e em meio dela, tão sugestiva a minha amizade e de Anita - ainda nos traz tristes e inconsoláveis. Por um filho, quem sabe, eu não sofreria tanto. Por esse acontecimento vejo o que me reservará o Jiqui, que felizmente goza saúde (citado em Tinoco, 1962, p. 114). ${ }^{3}$

Impacta a frase de Nilo, que a essa altura já tinha perdido crianças suas, "Por um filho, quem sabe, eu não sofreria tanto". Seus animais de estimação integravam a constelação dos afetos familiares, amados e pranteados individualmente. Jicky já existia e ocupava o primeiro lugar no coração de Nilo, que antevia o sofrimento causado pela sua perda no futuro. Até aqui traçamos um quadro da vida de Nilo Peçanha que ajuda a compreender sua inclinação para os animais. A composição da figura de Jicky exige maior detalhamento, pela dispersão dos indícios documentais e pelo ineditismo da proposta. Buscamos traços que revelem algo sobre suas condições materiais de vida e sua relação com outros seres.

Desde o final do século XIX o Brasil assistiu à criação de sociedades protetoras dos animais (Ostos, 2017), indicativo de que a sensibilidade sobre os bichos, principalmente no meio urbano, era um fenômeno social em mutação. Os cães, apreciados pela função de guarda, passaram a ser depositários de expectativas afetivas, inflexão que exigiu adaptações de humanos e bichos, indicando que a domesticação não é processo definitivo, e sim movimento contínuo, alinhado com o contexto histórico. Os bichos de companhia passaram a integrar a esfera privada, o ambiente doméstico restrito, frequentando espaços (quartos, sala), vedados aos cães de guarda, cujo lugar era o quintal. Para além desses limites viviam os cães de rua, muitas vezes repudiados por representarem descontrole e sujeira. Ao mesmo tempo, crescia o interesse pelos cães de raça (indicador de poder aquisitivo), cada animal simboli-

${ }^{3}$ Na obra de Tinoco a carta é referenciada como de outubro de 1901. 
zando uma qualidade ou papel no esquema doméstico: guarda, parceiro de brincadeiras para crianças, companhia de mulheres abastadas etc. (Aprobato Filho, 2007, p. 156).

Como Jicky se encaixava no contexto das relações entre humanos e cachorros nesse período? De acordo com Brígido Tinoco, o cão foi um presente dado a Nilo pelo político Eurico Coelho (1962, p. 139), deputado constituinte do Rio de Janeiro. ${ }^{4}$ É provável que tenha chegado ainda filhote, pois se em 1901 ele já estava com Nilo Peçanha, e tendo morrido em 1913, o cachorro viveu dentro da expectativa média de um cão bem cuidado dos dias de hoje. De pequeno porte e pelagem branca, ele foi designado como "cãozinho havanês" (Tinoco, 1962, p. 139), mas se assemelhava mais a um poodle. O certo é que era um cachorro com pedigree, até porque, na economia das relações sociais da época, em se tratando de membros da elite, o presente, pelo valor simbólico (monetário e pessoal), representava o apreço que se desejava transmitir. Jicky surge no cerne das relações políticas de Nilo Peçanha.

O nome do cachorro vem, provavelmente, do famoso perfume Jicky, criado em 1889 pelo francês Aimé Guerlain, e produzido até hoje (Turin, Sanchez, 2008, p. 212-213). Para um cão de raça correspondia uma alcunha elegante, referência francesa conhecida no círculo da elite, evidência da posição privilegiada dos donos. Ao contrário dos cães de rua, que cheiravam mal, esse animal deveria emanar bons eflúvios, ou assim se pretendia. A imprensa produziu alguns trocadilhos com o nome: “- Vens do Catete?/- Eu, não. / - Pensava - estás cheirando a Jicky...". Sendo um animal de raça, ele assumiu o papel de lulu ou loulou, expressão usada para designar cães pequenos, de pedigree, que gozavam da preferência dos donos. A primeira regalia concedida a esses animais era o acesso a recintos vedados a outros bichos. Jicky frequentava não apenas o quintal do Catete, como a área interna, e os jornais informavam que ele acompanhava o presidente até mesmo quando ele recebia políticos.

Na imagem abaixo, publicada na revista A Rua, testemunhamos como Jicky povoou as páginas da imprensa. O título, Actualidades, demonstrava a popularidade do cão. Abaixo da fotografia constava seu nome (personagem individualizado), e a legenda: "bom amigo do Palácio e dois... amigos do Palácio”. Não há descrição suplementar, revelando que o cachorro era conhecido do público. A imagem centralizou a figura de Jicky, protagonista que dispensava coadjuvantes. Sua posição privilegiada se revelava pelo fato de ter sido colocado sobre uma elegante cadeira, artefato de uso humano, ficando acima do chão, terreno dos cães comuns. A legenda faz referência às amizades do cão no Catete. Assim, ele ocupava não apenas o centro da imagem, como também se situava no âmago do mundo político e das relações de poder da época.

\footnotetext{
${ }^{4}$ Eleições. Goyaz, órgão do Partido Liberal, ano VI, n. 263, 3 out. 1890, p. 1. Em listagens recentes esse deputado consta como Erico Marinho da Gama Coelho e não Eurico, mas nas fontes ele aparece como Eurico. Natural de Cabo Frio, RJ, o político manteve algum tipo de articulação com Nilo Peçanha.

${ }^{5}$ Agulhas e alfinetes. O Século, Rio de Janeiro, ano IV, n. 961, 11 out. 1909, p. 1.
} 
Figura 1 - Reprodução de fotografia de Jicky

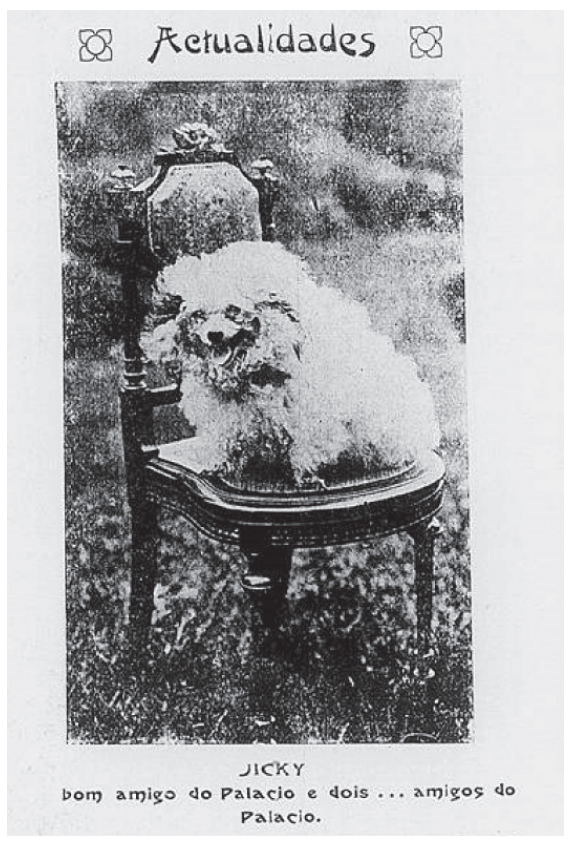

Fonte: A Rua, Rio de Janeiro, ano I, n. 2, 28 abr. 1910, s.p.; Hemeroteca Digital/Biblioteca Nacional.

Jicky entrou para a família Peçanha ainda filhote e foi socializado com humanos e outros animais. Estava acostumado à presença de estranhos, o que provavelmente ajudou-o a desenvolver personalidade afável, já que um cão agressivo não seria admitido na convivência social. O cachorro frequentava tanto as dependências íntimas da família quanto locais da casa destinados ao trabalho de Nilo e à recepção de visitas, tornando-o conhecido da imprensa e do público. A revista Careta alude, em tom de troça, à popularidade de Jicky em meio à ascensão de Nilo Peçanha: "Políticos que nunca o afagavam porque nunca iam a Icarahy disputam, hoje, a honra de alisar-lhe os pelos da cauda. Querem-no todos, hoje" ${ }^{6}$ Como cão de colo, ele deveria ser limpo e manso, para não incomodar as pessoas com odores desagradáveis e agitação excessiva. Apesar de Jicky possuir instrumentos de contenção, o fato de aparecer solto nas imagens, revela que ele foi de tal modo socializado que era capaz de comportar-se bem em liberdade. Quanto mais próximo do contato humano, mais "O cachorro deveria se civilizar. Seu corpo deveria ser controlado" (Baldin, 2014, p. 95; tradução da autora).

Os cuidados dispensados a Jicky contrastavam com a vida dos cães "comuns". No início do século XX não existia uma alimentação específica para os cachorros, como a ração. Eles

${ }^{6}$ Pegar no rabo do Jicky. Careta, Rio de Janeiro, ano II, n. 59, 17 jun. 1909, s.p. 
eram alimentados com sobras da cozinha, ossos ou uma mistura barata, como o angu. Já os animais de estimação das pessoas abastadas, além do alimento corriqueiro, costumavam ser mimados com quitutes. O partilhar da comida requintada evidenciava a proximidade e o status do animal para o dono. No caso de Jicky, várias notas da imprensa faziam referência à sua alimentação luxuosa, "O sr. Nilo Peçanha prepara a vitória do amigo que levava bombons para o Jicky". ‘ Em crônica, um jornal especulava sobre os pratos oferecidos ao animal, "é um cachorrinho palaciano [...] almoça camarões recheados". ${ }^{8}$

No que diz respeito à saúde dos bichos, até o início do século XX os cuidados veterinários no Brasil vinculavam-se aos saberes das escolas agrícolas e ao ofício da alveitaria, arte de curar animais, principalmente cavalos. A medicina veterinária, mesmo na Europa, configurou uma expertise a partir da segunda metade do século XVIII, distinguindo-se, "não sem dificuldade, das práticas empíricas da medicina popular e dos saberes artesanais dos mestres-ferradores" (Baldin, 2014, p. 108; tradução da autora). A profissão veterinária ganhou contorno no Brasil a partir da década de 1910, formalizada justamente por Nilo Peçanha, ${ }^{9}$ com a abertura, no Distrito Federal, da Escola Superior de Agricultura e Medicina Veterinária. Na descrição das cadeiras do curso de veterinária nota-se que o tradicional interesse para com os animais de produção não era o único mote, incluindo "Anatomia comparada, principalmente dos pequenos animaes domésticos" e "Clinica médica dos pequenos animaes". Com a popularização dos bichos de estimação, cresceu a necessidade de cuidados especializados, situação que Nilo conheceu de perto ao recorrer, em 1901, aos serviços de um médico de humanos para tratar seu cachorro doente..$^{10}$

Jicky foi um cão longevo, mas não escapou de indisposições e doenças. O jornal O Correio da Manhã noticiou que, durante viagem com os donos, Jicky "teve lá uma pneumonia, correndo grande risco a sua vida". "Brígido Tinoco narra que Pinheiro Machado, em visita ao político fluminense, testemunhou Nilo "preocupadíssimo com a enfermidade de Jiqui", tendo dito, "vou curar agora mesmo o teu cachorro. [...] E, ato contínuo, apesar dos protestos de Nilo, coloca a cabeça do Jiqui debaixo da pia. O jorro de água fresca reanima o pequeno animal em rápidos instantes" (1962, p. 139). Importa menos a certeza do episódio, e sim o que ele evidencia; como o fato de que uma das formas de agradar Nilo era mostrar simpatia por seu

\footnotetext{
${ }^{7}$ O Século, Rio de Janeiro, ano III, n. 7.012, 22 dez. 1908, p. 1. Itálico no original.

${ }^{8}$ Correio da Manhã, Rio de Janeiro, ano IX, n. 2.993, 26 set. 1909, p. 1. Itálico no original.

9 O presidente, membro das elites fluminenses, desejava a diversificação da agricultura como forma de contornar as oscilações da economia do seu estado, ao mesmo tempo em que almejava fazer um contraponto ao predomínio dos cafeicultores, encarnados no poder político de São Paulo. Ele criou o Ministério da Agricultura, Indústria e Comércio; decreto n. 7.501, de 12 ago. 1909.

10 Decreto 8.319, 20 out. 1910, art. 5, art. 7, art. 12, art. 13, art. 14.

${ }^{11}$ O Jicky. Correio da Manhã, Rio de Janeiro, ano XI, n. 3.981, 12 jun. 1912, p. 1.
} 
cão. A anedota estava em sintonia com a descrição do caráter de Pinheiro Machado, autoritário, pragmático e resoluto (Faoro, 2001, p. 682-711). A suposta brusquidão de Pinheiro insinuava a contraposição de estilos políticos diferentes, pois os admiradores de Nilo gostavam de caracterizá-lo como amável. O detalhamento do episódio parece um recurso do biógrafo para apontar incompatibilidades latentes, prenúncio do rompimento entre os dois líderes, que ocorreu em razão de discordâncias políticas acumuladas (Ferreira, s.d, s.p.).

Tendo em vista os traços selecionados da vida de Nilo Peçanha e Jicky, o que podemos dizer sobre essa relação em termos pessoais e culturais? Porque esse animal, e não outro, foi o companheiro de Nilo, seu "cão público"? A chegada de Jicky, filhote, quando o casal sofria revés pelo falecimento de filhos, pode ter gerado maior apego ao bicho. Contava a seu favor o fato de ser cão de raça, de pequeno porte, fácil de restringir e acompanhar os donos. Ao longo do século XIX o debate sobre as "raças humanas" foi central no mundo intelectual e político (Schwarcz, 1993). A raça como referência biológica direcionava a discussão para aspectos sociais, como a "qualidade" das linhagens humanas, atributos culturais e intelectuais. No caso do Brasil, essa discussão partiu da realidade de um país miscigenado, mas a noção de "pureza racial" não deixou de ser um ideal. Nilo Peçanha, homem negro, sofreu ataques racistas. Ele era chamado na imprensa de "moleque do Catete", "moleque presepeiro", sendo que a palavra moleque se refere a um garoto jovem, negro (Lustosa, 1989, p. 56). Em discurso proferido no recinto legislativo e publicado na imprensa, o senador Alfredo Ellis atacou o então presidente Nilo Peçanha: "o governo da República foi ter às mãos de uma quadrilha em que se encontram todos os tipos de criminosos, desde o nato, de cabelos crespos e dentadura a limpa-trilhos [...]"..12 Outro artigo assim se referiu ao político: "O sr. Nilo é um êmulo de Justino, o caricato Imperador do Haiti”. ${ }^{13}$ As referências são explícitas, a condição de negro foi ligada à de criminoso, inferência comum na criminologia da época; a descrição dos traços físicos, considerados "inferiores" no repertório racista, buscava humilhar o adversário. A homogeneização das pessoas negras levou à comparação de Nilo com o governante do Haiti (país de maioria negra), taxado de "caricatura", isto é, imagem distorcida de um modelo.

Em fins do século XIX multiplicaram-se as organizações de cinofilia, preocupadas em registrar cuidadosamente as raças e linhagens de cães, pois a estirpe do animal distinguia socialmente os proprietários (Ritvo, 1986, p. 240-243). Jicky era qualificado pelos impressos

\footnotetext{
${ }^{12}$ O governo e as docas de Santos. Discurso proferido no Senado pelo sr. Alfredo Ellis, na sessão de 12 do corrente. Correio da Manhã, Rio de Janeiro, n. 3.406, 14 nov. 1910, p. 3. Itálico no original.

13 O moleque no Catete (Do Correio do Brasil). Jornal do Commercio, Rio de Janeiro, n. 210, 29 jul. 1910, p. 6. A referência é provavelmente a Faustino (Faustin-Élie Soulouque), e não Justino, autoproclamado imperador do Haiti em meados do século XIX (Lopes, 2011, s.p.).
} 
como "de raça [...] muito limpinho". ${ }^{14}$ Mas na documentação encontramos passagem que questionou a "pureza" de Jicky: "Dr. Nilo Peçanha. - Podemos garantir a V. Ex. que o Jicky é um puro... rói osso, ou street dog". ${ }^{15}$ Ao contestar a procedência do animal, tipificando-o como cachorro de rua, sem pedigree, comedor de restos, inferia-se que o cão era uma farsa. Acreditamos tratar-se de um deslizamento de sentidos, referência velada à origem do próprio Nilo. Seria ele um"desqualificado", "rói osso" dos restos deixados por Afonso Pena?

Mas as menções na imprensa a Jicky e Nilo assumiram tons variados. A Figura 2 retratou Nilo Peçanha com o cão. O título, "Trocadilho presidencial", compunha com a legenda: "- O meu Jicky de estimação, é um canino incisivo que nunca pode amolar, mesmo quando vos queixais". A brincadeira fez um jogo de palavras com referência a dentes, alusão ao poder dos cães de morder, e que Jicky, mesmo podendo incomodar terceiros, tinha o carinho do presidente. A fotografia mostrava um Nilo Peçanha composto. Mas o convencionalismo da pose foi quebrado pela presença do cão, acomodado nas pernas do dono, figura inusitada. Jicky é o centro da imagem que, sem ele, seria comum. Para o público, o poder representado pelo presidente da República se adoçava na expressão de seu afeto por um cãozinho.

Figura 2 - Nilo Peçanha com Jicky

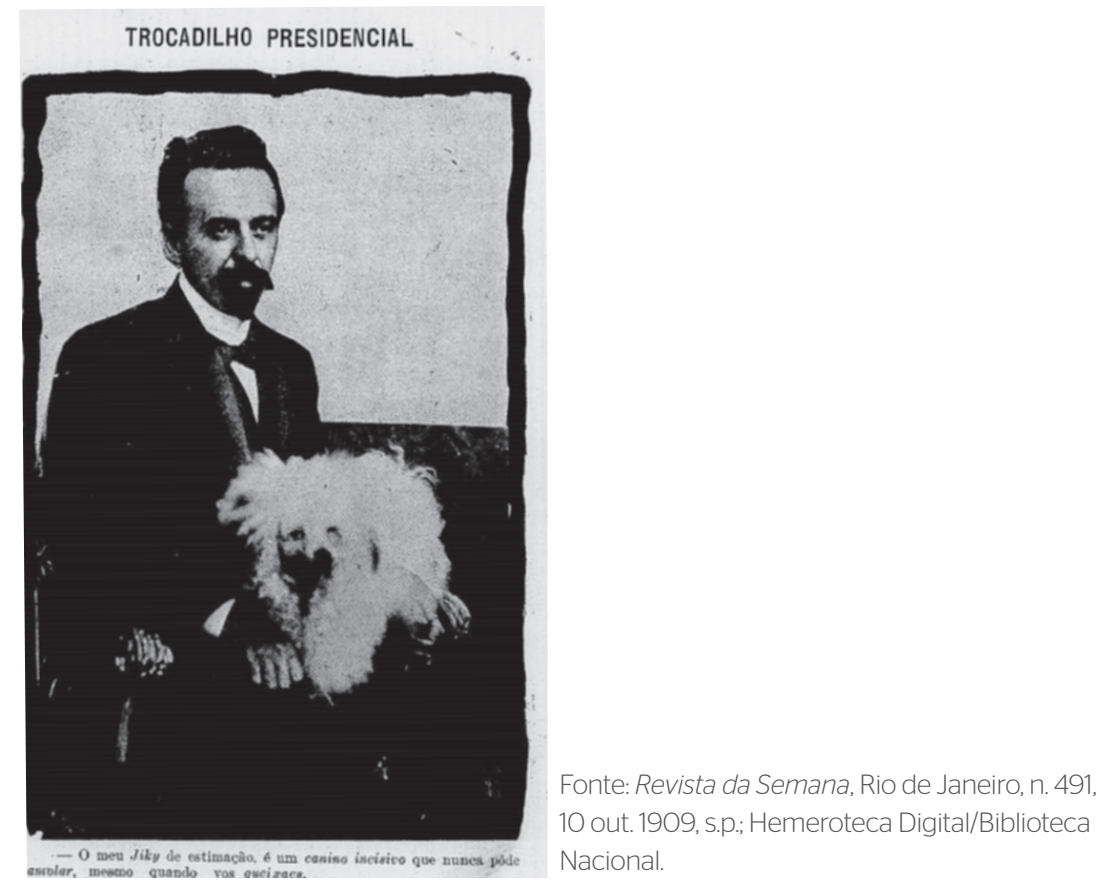

${ }^{14}$ Fon-Fon, Rio de Janeiro, ano III, n. 31, 31 jul. 1909, s.p.

${ }^{15}$ Dr. Vaz-Com-Sellos. Caixa Postal. Revista da Semana, Rio de Janeiro, ano III, n. 481, 1 ago. 1909, s.p. 
Argumentamos que Nilo Peçanha e Jicky, longe de estarem destinados a se encontrar, expressavam características materiais, culturais e afetivas que transformaram essa união em uma relação duradoura e de sucesso, a tal ponto que ela se prestou a produzir sentidos para além do âmbito privado. Jicky era um elemento que se encaixava na imagem que Nilo procurou construir para si. Não esqueçamos que ao assumir a Presidência ele o fez sob o lema: "farei um Governo de paz e amor". ${ }^{16}$ Para além do afeto que Nilo devotava a Jicky, este foi o escolhido, dentre outros animais, para aparecer junto dele em ocasiões públicas. O cachorro poderia nunca ter saído do âmbito privado, mas Nilo optou por publicizar a relação, posando com Jicky para fotografias e mantendo o cão em sua presença mesmo quando recebia políticos. A dimensão pública dessa convivência ajudou a plasmar a imagem de Nilo Peçanha como líder acessível e caloroso, e serviu de suporte para a imprensa criar textos e charges com diversas referências ao mundo político.

\section{Jicky, um animal político}

Na história não é raro o registro de líderes que possuíam bichos de estimação (Pastoureau, 2015, p. 181-186). No século XIX temos o emblemático caso da rainha Vitória da Inglaterra, que ajudou a popularizar os animais de companhia em razão do seu conhecido afeto por cães, processo favorecido pelas fotografias que circulavam da soberana com seus bichos (Rappaport, 2003, p. 34). Manter um animal de estimação deixou de ser, gradualmente, uma prerrogativa de nobres, espraiando-se para a burguesia em um período em que, "A imagem aristocrática de um animal de companhia, emblema de luxo [...] se estilhaça em um fenômeno mais complexo, no qual a afeição é reivindicada como uma necessidade social" (Baldin, 2014, p. 270; tradução e destaque da autora).

Richard Sennett argumenta que, a partir do século XIX, "uma figura pública apresenta aos outros aquilo que sente", e que essas "relações íntimas [...] determinam aquilo que será crível" para o público (1988, p. 42, p. 55). Em tal cenário, de esvaziamento da esfera pública, importa cada vez mais que os políticos mostrem sua personalidade e inclinações pessoais, mesmo que tal "proximidade" não contribua, necessariamente, para o diálogo público. No decorrer do século XX o cão se torna expressão de uma vida íntima calorosa e da capacidade afetiva do dono, constelando noções de fidelidade, carinho e companheirismo. Nos dias

\footnotetext{
${ }^{16}$ Em uma entrevista Nilo afirmou: “[... FAREI TUDO PARA QUE SE RESTABELEÇA A CONCÓRDIA ENTRE OS BRASILEIROS. GOVERNO DE PAZE AMOR!". A Notícia, Rio de Janeiro, ano XVI, n. 134, 14 jun. 1909, p. 1. (transcrito como no original). A expressão caiu no gosto popular e foi mote para um filme, Paz e amor, lançado em 1910, de grande sucesso, comédia musical com referências a figuras políticas, como o rei Olin I, que é Nilo ao contrário.
} 
atuais vários líderes políticos instrumentalizam tal positividade para angariar a simpatia dos eleitores, apresentando seus animais de estimação ao público.17

Warren Harding é tido como o presidente (1921-1923) que criou a figura do "primeiro cão" nos Estados Unidos da América. Coincidentemente, assim como Nilo Peçanha, o casal presidencial não possuía filhos, de modo que o cachorro de raça, Laddie Boy, tornou-se veículo da afetividade dos dois e testemunho público de sua bondade (Pycior, 2005, p. 112). Harding era tido como um homem afável, que gostava de confraternizar com as pessoas e receber a imprensa na Casa Branca. Laddie Boy participava de eventos na residência oficial, criando um clima de alegria e informalidade que cativava o público e os jornalistas. O cão fez tanto sucesso que passou a ter "voz própria", respondendo cartas, concedendo entrevistas e posando para fotografias (Pycior, 2005, p. 117, 127-128). A partir de então vários presidentes estadunidenses tiveram um animal de estimação que acumulava funções públicas. O caso de Jicky e Nilo Peçanha foi anterior a Harding e seu Laddie Boy, mas não inaugurou uma tradição, talvez por isso o sucesso da relação tenha caído no esquecimento.

$\mathrm{Na}$ época, Jicky figurava na imprensa como argumento narrativo, pretexto para abordar práticas sociais e políticas, a exemplo da bajulação dos poderosos. $\mathrm{O}$ ato de lisonjear, com o intuito de angariar vantagem, possuía terminologias populares, como "engrossar". Com a ascensão de Nilo à Presidência, transformando-o em figura central da política nacional, a imprensa cunhou um novo termo para se referir ao servilismo político: "pegar no rabinho do Jicky". ${ }^{18}$ Na gramática do poder, tudo aquilo que tem relação com o líder passa a ser elemento do teatro político. Jicky "foi um cão [...] Hoje é quase um homem, é uma personagem, um fetiche, é um porte-bonheur". ${ }^{19}$ Contaminado pela posição do dono, o cachorro foi elevado de sua condição "inferior", de bicho, ganhando relevo na economia das trocas simbólicas. A charge apresentada na Figura 3 expressou bem como a proximidade com Nilo (junto a seu coração), inscreveu o cão no vocabulário político. ${ }^{20}$ Fazer festa em Jicky era o novo "beija-mão", em reconhecimento à renovação dos simbolismos que acompanha a ascensão de um líder.

\footnotetext{
17 A lista é vasta, incluindo nomes como Barack Obama, Emmanuel Macron, George Bush. Em período mais recente temos o caso de Dylan, cão do presidente argentino Alberto Fernández, sucesso na campanha eleitoral de 2019, com perfil próprio no Instagram e mais de 291 mil seguidores. Na rede social o cão "se descreve" como melhor amigo do presidente e "Soy um collie nacional y popular". In: Instagram: dylanferdezok.

18 Pingos e respingos. Correio da Manhã, Rio de Janeiro, ano IX, n. 2.995, 28 set. 1909, p. 1.

19 Pegar no rabo do Jicky. Careta, Rio de Janeiro, ano II, n. 59, 17 jul. 1909, s.p.

20 Transcrição da legenda da Figura 3 (destaques no original): "Nilo - Meus senhores, agora não é mais - o bico da chaleira; mas sim, - o focinho do Jicky. Estão, portanto, prevenidos”. Na gíria da época, "Pega na chaleira”, "vem dum hábito doméstico - quando a criadagem quer testemunhar amizade à patroa, ou a quer engrossar, há sempre algum criado que tem o porfiado interesse em ser o primeiro a pegar na chaleira para servir a dona de casa. Assim, o termo significa adular, bajular". Castro Lopes, A última criação da gíria. Fon-Fon, Rio de Janeiro, ano III, fev. 1909, s.p. A expressão esteve em voga como referência aos aduladores de Pinheiro Machado, senador gaúcho, associado ao hábito de beber chimar-
} 
Figura 3 - Charge representando

Nilo Peçanha e Jicky

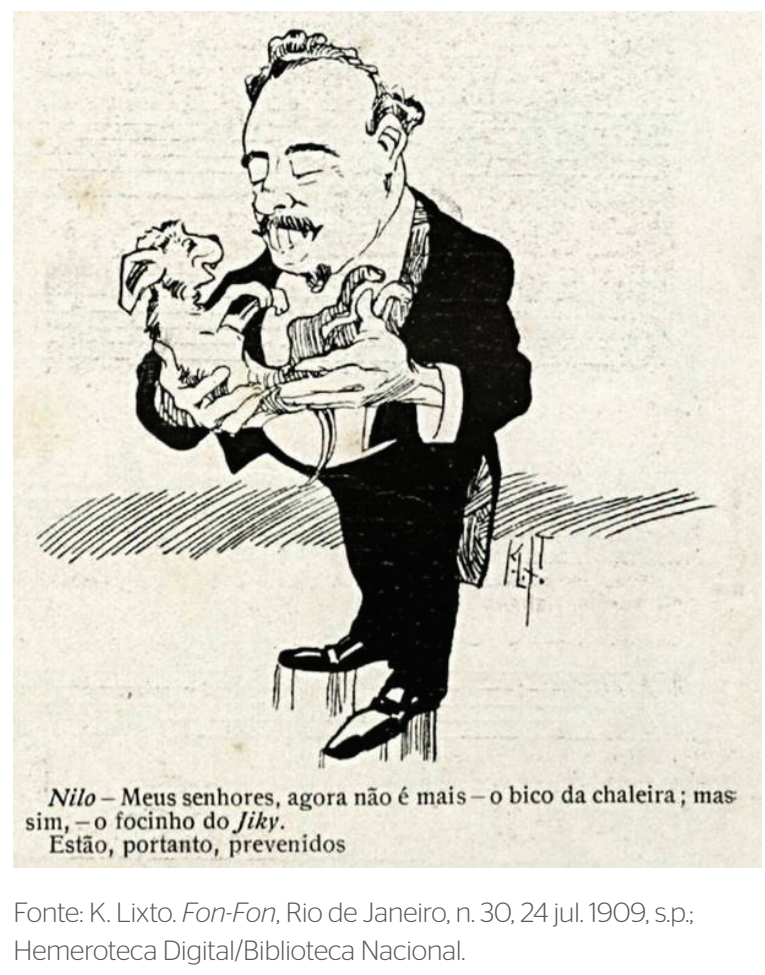

Ainda que no plano ideal se separe a esfera particular da pública, é ingênuo presumir que essas instâncias não se comunicam, e isso para além das análises que recobrem a tradicional mistura no Brasil entre o privado e o público (DaMatta, 1997). No mundo político da Primeira República, atravessado pelas relações pessoais, "ter conhecimento sobre os aspectos privados, os passatempos cultivados, os laços familiares existentes, as antipatias e simpatias [...] não constituíam informações fúteis ou curiosidade inútil. Pelo contrário, ser capaz de mobilizar essas peculiaridades pessoais era ferramenta importante no trânsito do mundo político" (Ostos, 2020, p. 119).

Jicky integrou o repertório simbólico de Nilo Peçanha, ajudando a plasmar, juntamente com outros elementos, a imagem de um político popular. Para Surama Pinto, a ideia de que Nilo buscou romper com a dinâmica dos arranjos políticos vigentes foi uma construção de

rão. É provável que a charge insinue que, com a ascensão de Nilo, formou-se um novo eixo de poder, relativizando a influência de Machado. 
seus biógrafos. Segundo a historiadora, ele "não diferia em essência dos políticos do seu tempo" (1998, p. 19), recorrendo aos mesmos expedientes usados pela elite política da época para disputar e manter o poder. Porém, no caso deste artigo se trata menos de corroborar historicamente, ou não, a excepcionalidade de Nilo, do que compreender como, na época, criou-se a percepção de um político acessível e supostamente benquisto pelo povo. Como já citado, o primeiro elemento evocado para a composição desse perfil era a origem modesta de Nilo Peçanha. Tal realidade e a ideia de que ele ascendeu sozinho, foram elementos importantes para a construção da imagem de homem simples. O fato é que Nilo Peçanha solidificou sua carreira política fazendo articulações com as oligarquias regionais. Ele também "criou laços de grande proximidade com as massas cariocas", mas, mesmo sendo um líder inegavelmente apreciado, principalmente na capital, seu prestígio também foi construído graças ao apoio de veículos da imprensa (Ferreira, 1993, p. 14).

Sua ascensão à Presidência da República representou uma mudança brusca no estilo dos ocupantes do Catete. Afonso Pena, idoso e discreto, entediava a imprensa ávida por acontecimentos sociais. Nilo Peçanha assumiu o cargo com 42 anos, e suas tendências joviais foram comemoradas como a chegada de uma nova geração ao poder. Com a morte de Pena, especulava-se se Nilo abandonaria os "exageros democráticos de só andar a pé ou de bonde passará a fazer uso das viaturas do Estado". ${ }^{21}$ Como que respondendo à imprensa, no mês seguinte o presidente foi flagrado "fazendo a pé o trajeto da Avenida Central, com grande pasmo da maioria dos transeuntes". ${ }^{22}$ Atitude celebrada como própria de um homem "simples [...] veio para a Rua, para a liberdade ampla da Rua, para o convívio nobre do Povo". ${ }^{23}$ Em uma República oligárquica, que prezava a hierarquia social, a quebra do protocolo era simpática e inusitada. O gesto de Nilo, ao contrário do que a revista pontuou, não significava uma atitude democrática, mas rompia a etiqueta do distanciamento entre os dirigentes e a população. Cabe lembrar que a Avenida Central era local de sociabilidade da elite.

Nilo também inovou no modo de receber no Catete, promovendo encontros animados, até mesmo um inédito garden party nas dependências externas do palácio, "a Presidência está hoje nas mãos de um moço [...]. É natural [...] que o venerando Palácio do Cattete abandone a sobriedade conselheiral do seu aspecto e apareça de vez em quando, festivo e alegre". ${ }^{24}$ O presidente cultivava os favores da imprensa, tratava bem seus profissionais, mostrando-se sabedor de sua influência na formação da opinião dos segmentos médios, "na recepção de palácio, Fon-Fon tivesse merecido distinções dignificadoras e frases de gentileza extre-

\footnotetext{
${ }^{21}$ Fon-Fon, Rio de Janeiro, ano III, n. 26, 26 jun. 1909, s.p.

22 Fon-Fon, Rio de Janeiro, ano III, n. 30, 24 jul. 1909, s.p.

23 Phoca Junior. Fon-Fon, Rio de Janeiro, ano III, n. 30, 24 jul. 1909, s.p.

24 Fon-Fon, Rio de Janeiro, ano III, n. 30, 24jul. 1909, s.p.
} 
mada do Sr. Presidente da República”. ${ }^{25}$ Nilo Peçanha alimentou a noção de que ele representava a novidade na política, isso apesar de integrar os quadros institucionais da República desde o início do regime. Sua juventude e o trato informal atraíam a curiosidade da imprensa e se afinavam com a efervescência urbana da cidade do Rio de Janeiro, cuja elite desejava atualizar seus códigos sociais de acordo com a moda europeia. A acessibilidade de Nilo e seus gostos de "homem comum" aproximaram-no das camadas médias urbanas, mesmo que apenas pela imagem. Em um regime político excludente, qualquer gesto de congraçamento se destacava, sendo confundido com noções de igualdade: "educado e amável, a alta posição que se acha, não lhe tirou o feitio democrata". ${ }^{26}$

O fato de Nilo Peçanha ser um político atento à construção da sua imagem não significa que suas preferências eram falsas, apenas que ele capitalizou traços de sua personalidade, interesses e gostos para disseminar certa atitude política. Nesse esquema, Jicky era um ingrediente útil para a narrativa de um líder que se queria amável e sociável. O lema "paz e amor" escolhido por Nilo Peçanha estava em perfeito acordo com o tipo de cãozinho que era Jicky, caloroso e abordável.

Na Figura 4, capa da revista O Malho, vemos Nilo Peçanha "Arrumando a Trouxa”, o título fazia referência a sua saída da Presidência para dar lugar ao recém-eleito Hermes da Fonseca. Na charge, Nilo porta uma roupa caseira, como que desvestido de sua posição oficial; ele arruma a mudança, com os acessórios de um homem importante espalhados no chão. Ao fundo a cadeira vazia da Presidência, aguardando o novo ocupante. Nilo conversa com uma figura ao fundo, o Zé Povo, representação comum na imprensa da época, personificação do povo brasileiro. Jicky acompanha Nilo no primeiro plano, ao seu lado, partilhando a sorte do dono, epítome da fidelidade canina. No diálogo, os protagonistas mencionam as agruras do cargo presidencial, e Zé Povo faz referência às instabilidades políticas que podiam surpreender os governantes. A última frase da legenda foi atribuída a Jicky, na imagem ele não participa da conversa, mas parece ouvir atentamente, como se compreendesse. Assim, na legenda, a sua "fala" expressava um pensamento: “O Jiky (favorito): - Hum!... Está me cheirando que o meu substituto será um buldog!...”. O cão foi qualificado pelo nome, "O Jicky", explicações sobre ele eram desnecessárias. A sua descrição como favorito de Nilo não era acidental, pois na sequência o animal especula que, se o Presidente Hermes escolhesse um cão, esse seria provavelmente um buldogue. Por que essa raça? Até meados do século XIX o bulldog era um cachorro usado em lutas com touros, tido como corajoso e feroz. Sua gradual incorporação como bicho de estimação (Ritvo, 1986, p. 244-245) não apagou a fama do animal. Assim, se o favorito de Nilo, presidente "paz e amor", era um cãozinho

\footnotetext{
${ }^{25}$ Sete dias de um neurastênico. Fon-Fon, Rio de Janeiro, ano III, n. 38, 18 set. 1909, s.p. Itálico no original.

26 Dr. Nilo Peçanha. Fon-Fon, Rio de Janeiro, ano III, n. 40, 2 out. 1909, s.p.
} 
doce e manso, a figura marcial de Hermes da Fonseca exigia um favorito que espelhasse sua personalidade, parrudo, de expressão fechada e fama de valente.

Figura 4 - Nilo Peçanha deixando a Presidência da República

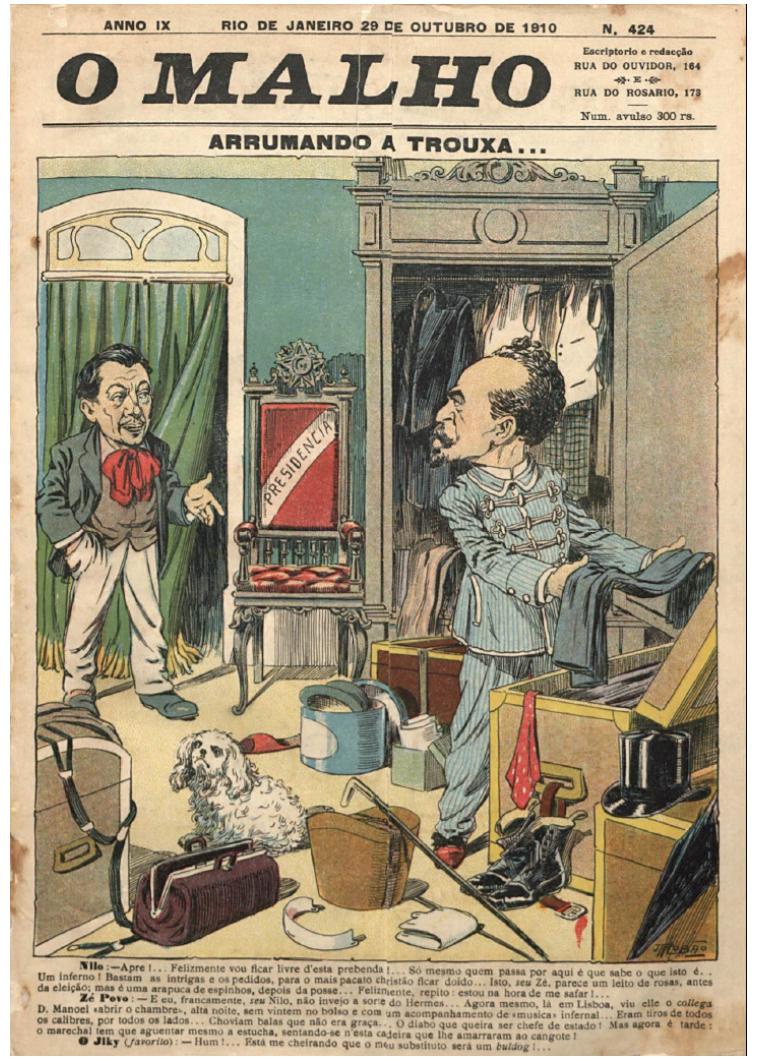

Fonte: O Malho, Rio de Janeiro, ano IX, n. 424, 29 out. 1910; Hemeroteca Digital/Biblioteca Nacional. ${ }^{27}$

27 Transcrição da legenda da Figura 4 (destaques no original): “Nilo: - Apre!... Felizmente vou ficar livre d'esta prebenda!... Só mesmo quem passa por aqui é que sabe o que isto é. Um inferno! Bastam as intrigas e os pedidos, para o mais pacato cristão ficar doido... Isto, seu Zé, parece um leito de rosas, antes da eleição; mas é uma arapuca de espinhos, depois da posse... Felizmente, repito: estou na hora de me safar!... / - Zé Povo: E eu, francamente, seu Nilo, não invejo a sorte do Hermes... Agora mesmo, lá em Lisboa, viu ele o collega D. Manoel, "abrir o chambre”, alta noite, sem vintém no bolso e com um acompanhamento de música infernal... Eram tiros de todos os calibres, por todos os lados... Choviam balas que não era graça... O diabo que queria ser chefe de Estado! Mas agora é tarde: o marechal tem que aguentar mesmo a estucha, sentando-se nesta cadeira que Ihe amarram ao cangote! / O Jiki (favorito): - Hum!... Está me cheirando que o meu substituto será um buldog!..." O episódio envolvendo D. Manoel se refere a sua deposição e à proclamação da República 
Jicky entrou no repertório de referências culturais e políticas da época, funcionando na imprensa como uma espécie de alter ego de Nilo Peçanha. Além da presença nos jornais, a popularidade do cão pode ser medida pelo fato do seu nome ser atribuído a outros animais, "desapareceu um cor de chocolate que dá pelo nome de Jicky, e tinha uma coleira de couro, é de estimação". ${ }^{28}$ Pedro Nava mencionou que circulava, na época, cartão-postal com a imagem do cão: "o que sei, porque tenho um, é dos postais que corriam o país com a figura do canino presidencial. O Jiqui" (Nava, 2001, p. 118). Mesmo com a saída de Nilo da Presidência, a imprensa continuou interessada no bicho. Em março de 1911, Nilo viajou com a esposa para a Europa, mas teve dificuldade para encontrar um navio que aceitasse o animal, "E, sem o cão predileto, o casal não conheceria a Europa. Finalmente, um paquete italiano concorda com a preciosa carga" (Tinoco, 1962, p. 178). As Figuras 5 e 6 mostram como Jicky estava totalmente integrado à vida do casal.

Figura 5 - Nilo e Anita Peçanha com Jicky

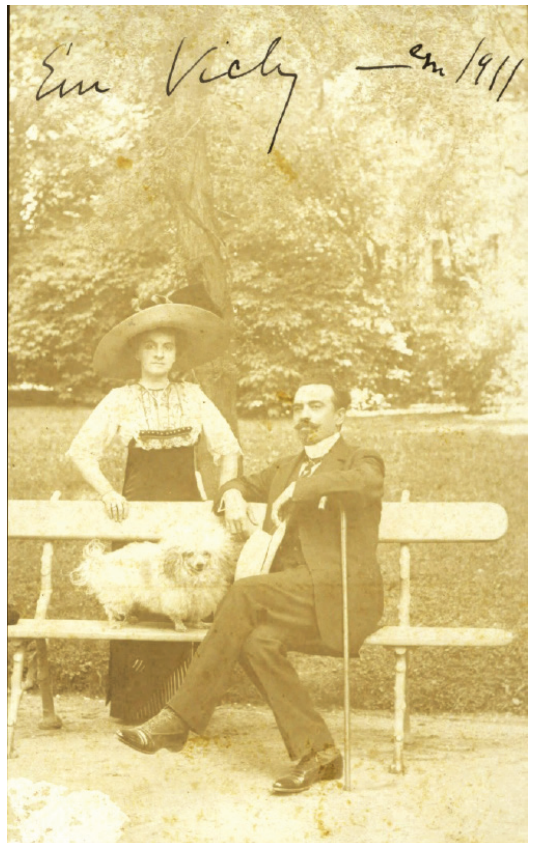

Figura 6 - Nilo e Jicky em uma viagem

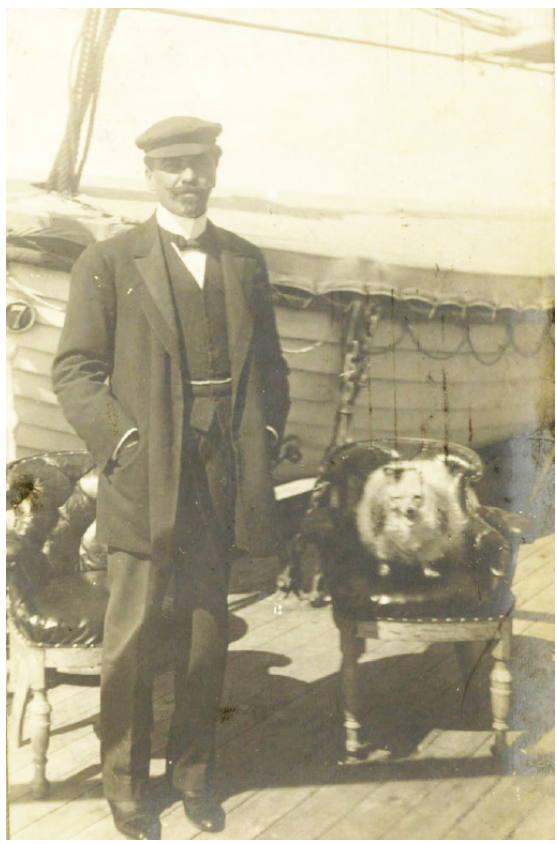

Fonte: Arquivo do Museu da República, Instituto Brasileiro de Museus/Ibram, Ministério da Cidadania (n. 39/2019); Coleção Nilo Peçanha, NP 540, Vichy, França (Figura 5), 1911 e Coleção Nilo Peçanha, NP 453, s.d. (Figura 6).

em Portugal, em 1910. Hermes da Fonseca estava em Lisboa na ocasião, tendo se encontrado com o rei um pouco antes dos acontecimentos. A revista O Malho era favorável a Hermes, caracterizando-o como homem de pulso forte.

${ }^{28}$ Cão Loulou. A Época, Rio de Janeiro, n. 872, 13 jan. 1915, p. 8. 
Na primeira fotografia (Figura 5), tirada na França, o cão aparecia como um membro da família, partilhando o banco com Nilo e tendo Anita ao fundo. Ele ocupava o lugar que seria tradicionalmente reservado a um filho (a imagem foi reproduzida na imprensa). ${ }^{29} \mathrm{Na}$ segunda fotografia (Figura 6), vemos um deque com duas poltronas, uma delas ocupada por Jicky, sempre que possível alçado ao nível do dono. A imprensa cobria os passos do cachorro em consonância com a agenda do político. Conta Brígido Tinoco que, em Nice, na França, durante jantar oferecido ao ex-presidente, tocaram o hino nacional brasileiro, "O Cãozinho Jiqui, [...] ergue-se de súbito, ao som do hino pátrio. Sustém-se nas patas traseiras e chega uma das patas dianteiras à cabeça, como se prestasse continência [...] apontavam-no como o fenômeno dos cachorros, como o cão mais patriota do mundo" (1962, p. 182). Não temos como corroborar o episódio, que do ponto de vista do treinamento animal seria exequível, mas o que interessa é que o cachorro foi revestido de atributos que, indiretamente, falavam não apenas sobre as qualidades do cão, mas também sobre a excepcionalidade de Nilo, do ponto de vista social e político.

\section{Conclusão e eco de duas vidas entrelaçadas}

Jicky morreu em 1913, e a imprensa repercutiu o fato, sugerindo que, se Nilo ainda fosse presidente, "o Jicky teria um artístico mausoléu, oferecido por subscrição entre amigos" ${ }^{30}$ Onze anos depois, em 1924, faleceu Nilo Peçanha, com apenas 56 anos de idade. Anita Peçanha sobreviveu ao marido por mais de três décadas, empenhando-se em honrar sua memória. Com suas doações formou-se a Coleção Nilo Peçanha no Museu Histórico Nacional, transferida para o Palácio do Catete quando este, em 1960, transformou-se em museu (Frecheiras, 2015, s.p.). O acervo foi acrescido ao longo dos anos, e em outubro de 1967 o Museu da República organizou uma exposição comemorativa do centenário de nascimento de Nilo Peçanha. A imprensa noticiou a exposição antes e após a inauguração, destacando que, dentre os documentos e objetos exibidos, "Não será esquecido [...] o cão Jicky, que Nilo Peçanha, conforme ele próprio dizia, cuidava como se fosse pessoa da família". ${ }^{31}$ A reportagem citou, na sequência, o suposto episódio em que o cão, na França, prestou continência ao hino nacional. Em 1967, o Brasil vivia sob uma ditadura militar que prezava o gestual patriótico, e a menção à encenação do animal parecia legitimar sua presença em um museu

\footnotetext{
${ }^{29}$ Fon-Fon! Em Vichy. Fon-Fon, Rio de Janeiro, ano V, n. 4, 27 jan. 1912, s.p. Legenda da imagem na revista: "Dr. Nilo Peçanha e sua Exma. senhora. Ao lado do ex-presidente da República o inseparável Jicky".

30 Do que se vai falar esta semana. Jornal do Commercio, Rio de Janeiro, n. 1.101, 12 maio 1913, p. 1.

${ }^{31}$ Exposição sobre Nilo Peçanha. O Jornal, Rio de Janeiro, n. 14.115, 1 out. 1967, p. 2.
} 
dedicado à República. Outras matérias descreveram a exposição: "Numa das vitrines estão as recordações de 'Jicky' [...] Um broche, com o retrato do cão, cercado de brilhantes, uma mecha do pelo, uma escultura de mármore representando o cão deitado";32 e ainda "um quadro a óleo, de Carlos Chambelland, [...] sua coleira e corrente de prata figurarão ao lado de objetos de Nilo Peçanha". ${ }^{33}$

A presença de animais em museus é comumente associada a mostras de caráter científico: "Historicamente institucionalizados, os animais tornaram-se objetos de museus, tão cedo as coleções surgiram. De forma que a trajetória dos museus de história natural está intimamente relacionada com a pesquisa em zoologia" (Soler, Landim, 2017, p. 271). Nesse tipo de museu, os animais (empalhados, com partes de corpos expostas etc.), normalmente figuram como representantes de uma espécie ou de um conceito científico, sendo raras as referências a "Detalhes individuais e/ou sua biografia" (Soler, Landim, 2017, p. 282-285). Claro está que Jicky ingressou no Museu da República como parte da coleção de Nilo Peçanha, mas a incorporação de seus objetos e a decisão de dedicar uma vitrine a ele foram escolhas importantes. Jicky não foi incluído em um museu de história natural, e sim no Museu da República, que apesar de não ter como único foco a política republicana, tendeu, inicialmente, a privilegiar a história institucional. O cão figurava, portanto, em meio aos próceres nacionais, como Getúlio Vargas e Epitácio Pessoa. Jicky já fora habitante do Catete, imprimiu sua marca em um local de forte carga simbólica, de modo que sua presença não parecia deslocada. Outro ponto importante é que no museu Jicky foi inscrito como indivíduo, claro que conectado a Nilo Peçanha, mas cuja existência gerou registros que dão testemunho da materialidade de uma vida específica.

No relatório geral do Museu da República estão listados objetos do cão ou relacionados a ele, dentro da Coleção Nilo Peçanha. O primeiro deles é uma pintura, óleo sobre tela, de uma figura animal, intitulada "Jicky", assim descrita: "Ao centro figura de cachorro branco, peludo. Cabeça de frente com fita no pescoço”. O quadro, sem data, de pequenas dimensões, é de autoria de Carlos Chambelland, ${ }^{34}$ artista reconhecido à época, formado na Escola Nacional de Belas Artes. O Museu da República possui fotografia do escritório de Nilo em que aparece o quadro de Jicky pendurado na parede, sinal do desejo de manter a lembrança do cão por perto. ${ }^{35}$ Também existe no acervo uma escultura, "estatueta animalística”, nomeada

\footnotetext{
32 Centenário de Nilo Peçanha. Jornal dos Sports, Rio de Janeiro, n. 11.984, 3 out. 1967, p. 3.

33 Mostra sobre Nilo Peçanha. Diário de Notícias, Rio de Janeiro, n. 13.765, 30 set. 1967, p. 9.

34 Museologia. Relatório geral. Num. Ref.: 1912, n. Inventário: 000.235. Coleção Nilo Peçanha, Museu da República.

${ }^{35}$ Fotografia: "NP 434- Aspecto do escritório de Nilo Peçanha em sua residência, localizada na Praia de Icaraí, 85, Niterói".

Coleção Nilo Peçanha, Museu da República.
} 
como "Jicky", de mármore branco, representando o animal sentado em uma almofada. ${ }^{36} \mathrm{Ou}$ tro item é um broche de ouro, cravejado de diamantes, com a "reprodução de cachorro poodle (Jicky) sentado". ${ }^{37}$ Constam, como de uso específico de Jicky: "a coleira usada pelo cão" ${ }^{38}$ e, como artigo de toalete, uma escova de dente, "de marfim. Cerdas de pelo animal". ${ }^{39}$ Por fim, está listada uma amostra de pelo natural do Jicky, "Chumaço de pelo de animal nas cores branco e bege", amarrado em tecido. ${ }^{40}$

Excetuando a escova de dente, todos esses objetos foram citados pela imprensa ao noticiar a vitrine dedicada à Jicky na exposição em homenagem a Nilo Peçanha. O conjunto de bens merece um estudo detalhado, impossível de ser feito nos limites deste artigo. Mas ele revela muitas possibilidades para a compreensão da vida do cão e da relação com os donos. Primeiro que Jicky era cuidado com todo o zelo, possuindo até escova de dente, item que mesmo nos dias de hoje não é incorporado por todos os donos de pets. Com cabo de marfim, o objeto distinguia a riqueza familiar e, juntamente com o broche, verdadeira joia (que se leva ao peito, próximo do coração), indicavam, pelo alto valor monetário, uma "quantificação" do afeto dispensado a Jicky. Não sabemos se o quadro, a escultura e o broche foram encomendas dos donos ou presente de terceiros, interessados em agradar Nilo. O certo é que são objetos caros, feitos de materiais nobres, de valor artístico, evidenciando o status incomparável do animal. A amostra de pelo de Jicky se assemelha à prática de cortar cachos de cabelos de entes queridos falecidos, para evocar lembranças de uma vida que passou.

Os objetos de Jicky estavam "Dentre as peças e espaços mais procurados pelos visitantes" no Museu da República (Frecheiras, 2015, s.p.). Talvez esse sucesso se deva menos ao estranhamento pela presença canina no local do que à satisfação de encontrar, em um museu, o reconhecimento material da afetividade partilhada por milhões de pessoas e animais. Os objetos expostos explicitavam tanto a concretude da existência do bicho, quanto relações culturais, afetivas e sociais. Legitimar, em um espaço cultural institucionalizado, a ligação entre um homem e seu cão, conferia espessura histórica a uma conexão muitas vezes invisível para os cânones do saber. O caso do presidente e seu cachorro indica que a convivência entre animais humanos e não humanos, individualizados, pode criar sentidos sociais. Mesmo que de forma implícita, e talvez inconsciente, foi o reconhecimento desse potencial afetivo e criativo que gerou, à época, a produção de tantas representações culturais e polí-

\footnotetext{
${ }^{36}$ Museologia. Relatório geral. Num. Ref.: 1499, n. Inventário: 001.432. Coleção Nilo Peçanha, Museu da República.

${ }^{37}$ Museologia. Relatório geral. Num. Ref: 36800, n. Inventário: 002.380. Coleção Nilo Peçanha, Museu da República.

${ }^{38}$ Museologia. Relatório geral. Num. Ref: 1912, n. Inventário: 000.235. Observações. Coleção Nilo Peçanha, Museu da República.

39 Museologia. Relatório geral. Num. Ref.: 36970, n. Inventário: 003.749. Coleção Nilo Peçanha, Museu da República.

40 Museologia. Relatório geral. Num. Ref.: 36969, n. Inventário: 003.748. Coleção Nilo Peçanha, Museu da República.
} 
ticas sobre Nilo Peçanha e Jicky, culminando na atribuição de estatuto museológico a uma relação de múltiplas significações. Cabe ao historiador atentar para aquilo que, como diz Carlo Ginzburg, salta "pela janela" (1989, p. 92), desafiando os percursos estabelecidos e anunciando a passagem daquele outro, cuja faceta se atualiza a cada momento histórico.

\section{Agradecimentos}

A autora agradece ao Museu da República, em especial à funcionária Silvia Pinho, pelo excelente atendimento. Agradece aos pareceristas anônimos, à Fiocruz Minas, à Fiotec, pelo financiamento, e aos colegas do Centro de Estudos dos Animais/CEA (Brasiliana: escritos e leituras da nação/UFMG), pela interlocução.

\section{Referências}

APROBATO FILHO, Nelson. O couro e o aço: sob a mira do moderno: a "aventura" dos animais pelos "jardins" da Paulicéia, final do século XIX/início do XX. Tese (Doutorado em História), Universidade de São Paulo. São Paulo, 2007.

BALDIN, Damien. Histoire des animaux domestiques, XIX-XX siècle. Paris: Seuil, 2014.

BARATAY, Éric. Biographies animales: des viés retrouvées. Paris: Seuil, 2017.

DAMATTA, Roberto. Carnavais, malandros e heróis: para uma sociologia do dilema brasileiro. Rio de Janeiro: Rocco, 1997.

DUARTE, Regina Horta. História dos animais no Brasil: tradições culturais, historiografia e transformação. Halac: Historia Ambiental, Latinoamericana y Caribeña, v. 9, n. 2, p. 16-44, 2019.

FAORO, Raymundo. Os donos do poder: formação do patronato político brasileiro. São Paulo: Globo, 2001.

FERREIRA, Marieta de Moraes. A Reação Republicana e a crise política dos anos 20. Estudos Históricos (Rio de Janeiro). v. 6, n. 1l, p. 9-23, 1993.

FERREIRA, Marieta de Moraes. Nilo Peçanha. Verbete. Rio de Janeiro: CPDOC/FGV, s.d. Disponível em: 〈https://cpdoc.fgv.br/sites/default/files/verbetes/ primeira-republica/PE\%C3\%87ANHA,\%20Nilo. pdf . Acesso em: 12 set. 2019.

FRECHEIRAS, Kátia. Do Palácio ao Museu: a trajetória pedagógica do Museu da República. [S.l.]: KBR Editora Digital, 2015.

FUDGE, Erica. Animal. London: Reaktion Books, 2002.

GINZBURG, Carlo. Mitos, emblemas, sinais: morfologia e história. São Paulo: Companhia das Letras, 1989.

LESTEL, Dominique; BRUNOIS, Florence; GAUNET, Florence. Etho-ethnology and ethno-ethology. Social Science Information (London). v. 2, n. 45, p. 155-177, 2006.

LOPES, Nei. Enciclopédia brasileira da diáspora africana. São Paulo: Selo Negro, 2011.

LUSTOSA, Isabel. Histórias de presidentes: a República no Catete. Rio de Janeiro; Petrópolis: Fundação Casa de Rui Barbosa; Vozes, 1989.

MELO, Demian de; FANAIA, João Edson. Joaquim Murtinho. Verbete. Rio de Janeiro: CPDOC/FGV, s.d. Disponível em: 〈https://cpdoc.fgv.br/sites/default/ files/verbetes/primeira-republica/MURTINHO,\%20 Joaquim.pdf>. Acesso em: 20 dez. 2019.

MOREL, Marco. As transformações dos espaços públicos: imprensa, atores políticos e sociabilidades na cidade imperial (1820-1840). São Paulo: Hucitec, 2005. 
NAVA, Pedro. Chão de ferro. São Paulo: Ateliê Editorial, 2001.

OSTOS, Natascha Stefania Carvalho de. União Internacional Protetora dos Animais de São Paulo: práticas, discursos e representações de uma entidade nas primeiras décadas do século XX. Revista Brasileira de História (São Paulo). v. 37, n. 75, p. 297-318, 2017.

OSTOS, Natascha Stefania Carvalho de. "Por que devemos ser bons para com os animais?". A formação prática e moral dos brasileiros por meio dos discursos de proteção aos animais (1930-1939). Historia Critica (Bogotá). n. 71, p. 49-68, 2019.

OSTOS, Natascha Stefania Carvalho de. Sociabilidade parlamentar em cena: atores políticos, cotidiano e imprensa na cidade do Rio de Janeiro (1902-1930). Belo Horizonte: Fino Traço, 2020.

PASTOUREAU, Michel. Os animais célebres. São Paulo: Martins Fontes, 2015.

PESAVENTO, Sandra Jatahy. Sensibilidades no tempo, tempo das sensibilidades. Nuevo Mundo Mundos Nuevos, Colloques, fev. 2005. Disponível em: 〈https:// journals.openedition.org/nuevomundo/229>. Acesso em: 31 maio 2021.

PINTO, Surama Conde Sá. A correspondência de Nilo Peçanha e a dinâmica política na Primeira República. Rio de Janeiro: Arquivo Público do Rio de Janeiro, 1998.
PYCIOR, Helena. The making of the "First Dog": President Warren G. Harding and Laddie Boy. Society \& Animals (Leiden). v. 13, n. 2, p. 108-138, 2005.

RAPPAPORT, Helen. Queen Victoria: a biographical companion. Santa Barbara: ABC-Clio, 2003.

RÉMOND, René (org.). Por uma história política. Rio de Janeiro: Editora FGV, 2003.

RITVO, Harriet. Pride and pedigree: the evolution of theVictorian dog fancy. Victorian Studies (Bloomington). v. 29, n. 2, p. 227-253, 1986.

SCHWARCZ, Lilia M. O espetáculo das raças: cientistas, instituições e questão racial no Brasil, 1870-1930. São Paulo: Companhia das Letras, 1993.

SENNETT, Richard. O declínio do homem público: as tiranias da intimidade. São Paulo: Companhia das Letras, 1988.

SOLER, Mariana Galera; LANDIM, Maria Isabel. O silêncio dos inocentes: o papel dos animais em narrativas expositivas. Anais do Museu Paulista (São Paulo). v. 25, n. 2, p. 269-289, 2017.

TINOCO, Brígido. A vida de Nilo Peçanha. São Paulo: José Olympio, 1962.

TURIN, Luca; SANCHEZ, Tania. Perfumes, the guide. London: Profile Books, 2008. 